\title{
Pressed into Party Support? Media Influence on Partisan Attitudes during the 2005 UK General Election Campaign
}

\author{
HEINZ BRANDENBURG AND MARCEL VAN EGMOND*
}

\begin{abstract}
This study reassesses the ability of the mass media to influence voter opinions directly. Combining data on media content with individuals' assessments of British political parties during the 2005 general election campaign allows a test of newspapers' persuasive influence in a way previously considered a 'virtual impossibility'. Utilizing repeated measures from the 2005 BES campaign panel, multilevel regression analysis reveals significant impact of partisan slant not just on the evaluation of the party mentioned but also on evaluations of its competitor(s). The strongest evidence of direct media persuasion is provided by the finding that variation in slant over the campaign drives how undecided voters evaluate the incumbent government party, even when controlling for a newspaper's average partisan slant.
\end{abstract}

The idea of the media as active persuader of the public has waxed and waned in media research over the past decades. The pervasiveness of the media is now accepted, but its persuasiveness is often dismissed. This article aims to challenge this notion, in line with recent work in political science and political communication investigating the conditions under which partisan bias and editorial comment can have a direct and directional impact on public opinion. ${ }^{1}$

* Department of Politics and International Relations, University of Aberdeen (email: h.brandenburg@ abdn.ac.uk); and Amsterdam School of Communications Research, University of Amsterdam, respectively. The authors are listed in alphabetical order. The authors would like to thank Robert A. Johns, Cees van der Eijk, Amanda Hosking, Bernhard Wessels and other participants of the WAPOR conference in Berlin in 2008, as well as participants of EPOP conferences in 2007 and 2008, and this Journal's three anonymous reviewers for their helpful comments and suggestions. An online appendix with supplementary tables and replication data is available at http://www.journals.cambridge.org/jps.

${ }^{1}$ Steven E Finkel, 'Reexamining the Minimal Effects Model in Recent Presidential Campaigns', Journal of Politics, 55 (1993), 1-21; Larry M. Bartels, 'Messages Received: The Political Impact of Media Exposure', American Political Science Review, 87 (1993), 267-85; Russell J. Dalton, Paul A. Beck and Robert Huckfeldt, 'Partisan Cues and the Media: Information Flows in the 1992 Presidential Election', American Political Science Review, 92 (1998), 111-26; Paul Allen Beck, Russell J. Dalton, Steven Greene and Robert Huckfeldt, 'The Social Calculus of Voting: Interpersonal, Media, and Organizational Influences on Presidential Choices', American Political Science Review, 96 (2002), 57-74; John Zaller, 'The Statistical Power of Election Studies to Detect Media Exposure Effects in Political Campaigns', Electoral Studies, 21 (2002), 297-329; Jochen Peter, 'Our Long Return to the Concept of Powerful Mass Media A Cross-National Comparative Investigation into the Effects of Consonant Media Coverage', International Journal of Public Opinion Research, 16 (2004), 144-68; James N. Druckman and Michael Parkin, 'The Impact of Media Bias: How Editorial Slant Affects Voters', Journal of Politics, 67 (2005), 1030-49; Pippa Norris, 'Did the Media Matter? Agenda-Setting, Persuasion and Mobilization Effects in the British General Election Campaign', British Politics, 1 (2006), 195-221; Claes H. De Vreese and Hajo G. Boomgarden, 'Media Message Flow and Interpersonal Communication: The Conditional Nature of Effects on Public Opinion', Communication Research, 33 (2006), 19-37; Jonathan McDonald Ladd and 
We build on the argument that media effects in general and persuasive effects in particular are "more fugitive than minimal' ${ }^{2}$ - showing that their fugitiveness is caused by an absence of suitable data, rather than the absence of substantial impact. We employ panel data on individual voters during the British general election campaignin 2005 and combine this with content analysis data of newspapers for the same period. This allows us to link individual voters to the printed media they were exposed to during the campaign and compare change in individual party preferences with media input during the campaign. The research design is a substantial step towards what Iyengar and Simon dubbed 'a virtual impossibility' little over a decade ago. ${ }^{3}$ By differentiating between overall partisan stances of newspapers and variation in their bias over the course of the campaign, we can distinguish the reinforcing and mobilizing functions of partisan media from their role in shaping and shifting attitudes. On that basis, we draw tentative conclusions about the extent to which media persuasion contributes to how undecided voters make an electoral choice.

\section{MEDIA PERSUASION: EXISTING RESEARCH}

The idea of media as persuaders is an old one, championed by Walter Lippmann who saw the press as an organizer (albeit ill-equipped) of public opinion, and by Harold Lasswell and Edward Bernays, who theorized about the effectiveness and pervasiveness of political and commercial propaganda. ${ }^{4}$ Such propositions about the role of propaganda, advertising and persuasive media impact were based on the assumption that audiences are passive and susceptible masses and hence that media and campaigns will impact directly on public attitudes and behaviour. ${ }^{5}$ The Columbia studies of presidential campaigns in the 1940s were seminal works in this field, providing the first systematic attempt to test such propositions empirically and, in the process, set the stage for decades to follow by establishing the minimal effects model. They found media messages not to be primary causes of opinion formation or change but instead to be bounded by and disseminated through social context. ${ }^{6}$ These findings of limited media impact served to discourage further research ${ }^{7}$, and their effect

(F'note continued)

Gabriel S. Lenz, 'Exploiting a Rare Communication Shift to Document the Persuasive Power of the News Media', American Journal of Political Science, 53 (2009), 394-410.

2 Bartels, 'Messages Received', p. 267.

3 Shanto Iyengar and Adam F. Simon, 'New Perspectives and Evidence on Political Communication and Campaign Effects', Annual Review of Psychology, 51 (2000), 149-69, p. 153.

4 Walter Lippmann, Public Opinion (New York: Free Press, 1922); Harold D. Lasswell, 'The Theory of Political Propaganda', American Political Science Review, 21 (1927), 627-31; Edward G. Bernays, Propaganda (New York: Horace Liveright, 1928).

5 Richard E. Petty, Christian Wheeler and Zakary L. Tormala, 'Persuasion and Attitude Change', in Theodore Millon and Melvin J. Lerner, eds, Handbook of Psychology. Volume 5: Personality and Social Psychology (Hoboken, N.J.: Wiley, 2003).

6 Paul E. Lazarsfeld, Bernard Berelson and Hazel Gaudet, The People's Choice (New York: Duell, Sloan and Pearce, 1944); Bernard R. Berelson, Paul F. Lazarfeld and William N. McPhee, Voting: A Study of Opinion Formation in a Presidential Campaign (Chicago: University of Chicago Press, 1954).

7 Bartels, 'Messages Received', p. 267. Indeed, only very few studies into media persuasion exist from the 1970s or 1980s. See, for example: Robert S. Erikson, 'The Influence of Newspaper Endorsements in Presidential Elections: The Case of 1964', American Journal of Political Science, 20 (1976), 207-33; Steven L. Coombs, 'Editorial Endorsements and Electoral Outcomes', in Michael B. MacKuen and Steven L. Coombs, More than News: Media Power in Public Affairs (Beverly Hills, Calif.: Sage, 1981); Joseph Wagner, 'Media Do Make a Difference: The Differential Impact of Mass Media in the 1976 Presidential Race', American Journal of Political Science, 27 (1983), 407-30. 
is still felt today, especially in electoral research in which the role of campaigns and mass media is still discounted by many. ${ }^{8}$

But there are good grounds to question the limited effects model and to argue that effects are not insubstantial but rather fugitive, i.e. difficult to detect. Bartels was the first to challenge the minimal effects model head-on. He argued that measurement error and limitations in research design, such as the short time-frames used in previous studies, made it virtually impossible to appreciate the potential scale of media impact on electoral choice. 9 In addition, Zaller has shown that detection of campaign and media effects depends not solely on their occurrence but crucially on survey size and model specifications. ${ }^{10}$ Further obstacles to a valid and reliable assessment of media effects may lie in the operationalization of media variables, the level of aggregation and the use of crosssectional rather than panel data.

Bartels and Zaller provide important starting points in this regard because, while challenging the minimal effects conclusions, they both remain within the paradigm of media exposure effects research that was pioneered by the Columbia studies. The idea behind this approach is that, if media is able to influence public opinion, then those who are consuming more news and political coverage should be more affected. Lazarsfeld and Berelson looked primarily for a switch in support for candidates over six waves of their panel study, expecting that those more exposed to media coverage would be observed to have switched more often between candidates, but concluded that for the most part campaigns merely 'preserve prior decisions instead of initiating new [ones]'. ${ }^{11}$ In essence, this approach does not study media persuasion because it only estimates the impact of being more or less exposed to the media and not the differential impact of the kind of media and messages to which one is exposed.

A resulting problem, typically encountered in but not exclusive to media exposure studies, is that media impact appears to remain limited because diverging messages tend to cancel each other out. ${ }^{12}$ This is a problem of aggregation - unless one were to assume that people are exposed to all diverging views presented by the media, or that people read the whole spectrum of views carried by the media in the specific outlet they favour. Both options are unlikely, meaning that media messages may well balance out at aggregate level but are unlikely to do so at individual level. Individual voters will be exposed to the particular views carried by their favoured outlets only, and divergent media messages cannot be an explanation for an absence of media effects. But data at the individual level are needed to show this. In the absence of such data, one has to exploit, as Erikson did, rare occasions like the 'break from homogeneous mass media treatments' in the 1964 US election to show media effects resulting from diverging media messages that unevenly distribute across local communities. ${ }^{13}$ In similar vein, the shift from a Tory press to a 'Tony press' in Britain during the mid-1990s inspired renewed research interest in media persuasion effects. ${ }^{14}$ Ladd and

${ }^{8}$ Norris, 'Did the Media Matter?'

9 Bartels, 'Messages Received'.

${ }^{10}$ John Zaller, 'The Statistical Power of Election Studies to Detect Media Exposure Effects'.

${ }^{11}$ Lazarsfeld et al., The People's Choice, p. 87.

12 John Zaller, The Origins and Nature of Mass Opinion (New York: Cambridge University Press, 1992); Bartels, 'Messages Received', p. 276.

${ }_{13}$ Erikson, 'The Influence of Newspaper Endorsements in Presidential Elections', p. 207.

${ }^{14}$ Colin Seymour-Ure, 'Editorial Opinion in the National Press', Parliamentary Affairs, 50 (1997), 586-608; Dominic Wring, 'The Tony press: media coverage of the election campaign', in A. Geddes and John Tongue, eds, Labour's Second Landslide (Manchester: Manchester University Press, 2001). 
Lenz convincingly demonstrate that some readers followed their paper's shift in allegiance from the Conservatives in 1992 to Labour in 1997..$^{15}$

Using endorsements to operationalize media input, as Ladd and Lenz did, presents an important step forward since they address the fact that some media, most notably newspapers, attempt to sway their audiences. A number of studies have found that newspaper endorsements, and changes thereof, have an impact on attitudes. ${ }^{16}$ Endorsements, and hence partisan tendencies, are also reflected in how a campaign is covered and the comments that are made on it in a newspaper. ${ }^{17}$ But studies of media impact that use endorsements as their independent variable tend to treat them as unambiguous and to model the newspaper as being in support of party A or candidate X, against party B or candidate Y. And, despite the fact that descriptive studies of newspaper endorsements increasingly emphasize variation and ambiguity by substituting simple dichotomous variables with typologies that allow for variation in strength and direction of endorsement, ${ }^{18}$ only a few of the scholars who study the impact of endorsements have adopted this approach. ${ }^{19}$ There is a further drawback to employing endorsements as proxies for actual persuasive media input: it ignores variation in slant over the course of a campaign. It is reasonable to assume that newspapers will vary not only with regard to the intensity of their persuasive intent but also with regard to the intensity and consistency of their persuasive effort. Persuasion is a process that requires variation and repetition of arguments in order to alter someone's state of mind, which is the precondition for persuasion to ultimately succeed. ${ }^{20}$

A more nuanced assessment of a newspaper's persuasive intent and effort captures the trajectory of the paper's endorsement over the course of the campaign, i.e. 'the quantity and tone of a media outlet's candidate coverage as influenced by its editorial position'. ${ }^{21}$ Content analysis of the media can provide us with objective measures of the judgements

15 Ladd and Lenz, 'Exploiting a Rare Communication Shift', p. 405.

${ }^{16}$ Harold F. Gosnell, Machine Politics: Chicago Model, 2nd edn (Chicago: University of Chicago Press, 1968[1937]); Erikson, 'The Influence of Newspaper Endorsements in Presidential Elections'; Coombs, 'Editorial Endorsements and Electoral Outcomes'; Wagner, 'Media Do Make a Difference'; Richard Webber, 'The 1992 General Election: Constituency Results and Local Patterns of National Newspaper Readership', Journal of Elections, Public Opinion \& Parties, 3 (1993), 205-15; John Curtice and Holli A. Semetko, 'Does It Matter What the Paper Say?' in Anthony Heath, Roger Jowell and John Curtice, eds, Labour Last Chance? (Aldershot, Surrey: Dartmouth, 1994); John Curtice, 'Is the Sun Shining on Tony Blair? The Electoral Influence of British Newspapers', Harvard International Journal of Press/Politics, 2 (1997), 9-26; Kenneth Newton and Malcolm Brynin, 'The National Press and Party Voting in the UK', Political Studies, 49 (2001), 265-85; Norris, 'Did the Media Matter?'; Ladd and Lenz, 'Exploiting a Rare Communication Shift'.

${ }^{17}$ Kim Fridkin Kahn and Patrick J. Kenney, 'The Slant of the News: How Editorial Endorsements Influence Campaign Coverage and Citizens' Views of Candidates', American Political Science Review, 96 (2002), 381-94.

18 David Deacon and Dominic Wring, 'Partisan Dealignment and the British Press', in John Bartle, Simon Atkinson and Roger Mortimore, eds, Political Communications: The General Election Campaign of 2001 (London: Frank Cass, 2002), pp. 197-214.

19 The use of an overly simplistic dichotomy that divides the press into Conservative v. Labour papers may explain why an earlier study of the 2005 British general election found only limited persuasion effects on party and leader evaluations or vote choice, with some of the significant estimates even pointing in the wrong direction; see Norris, 'Did the Media Matter?', pp. 210-13.

20 David W. Schumann, Richard E. Petty and D. Scott Clemons, 'Predicting the Effectiveness of Different Strategies of Advertising Variation: A Test of the Repetition-Variation Hypothesis', Journal of Consumer Research, 17 (1990), 192-202.

21 Druckman and Parkin, 'The Impact of Media Bias', p. 1030. 
and opinions addressed to a paper's readers, describing the extent of partisan slant and its variation over time. An increasing number of researchers opt for such content analysis measures as input variables. When combined with cross-sectional survey data, which allow control for partisan predispositions, almost invariably these measures suggest a direct impact of media messages on partisan attitudes or vote choice. ${ }^{22}$ Such studies examine 'differences in coverage, and ultimately, if these differences affect voters'. ${ }^{23}$ While these studies successfully address the varied nature of persuasive efforts, their findings remain tenuous because the use of cross-sectional survey data does not allow adequate modelling of the receiving end of persuasion - the readers and the process of being persuaded.

Persuasion - a dynamic process - cannot be established through the use of stationary data. Some researchers address this by simulating how public opinion moves from an initially observed original state in response to directional media stimuli, others by studying variation in media effects measured over the course of a campaign through the use of rolling cross-sectional surveys. ${ }^{24}$ Both approaches result in findings of substantial media impact. However, since media persuasion is an individual-level process, we cannot properly assess the extent of its impact from aggregate-level shifts in partisan support. Individual-level panel data are therefore required. Kleinnijenhuis et al. use an impressive thirteen waves of the Dutch Telepanel study during the 1998 campaign and a smaller panel study from the German election campaign in 1998 to show that, in both countries, media presentation of issue developments helps issue-owning parties and that all parties are affected by positive or negative coverage of their party leaders. ${ }^{25}$ De Vreese and Boomgaarden take another significant step forward by moving from aggregate-level to individual-level analysis of media-induced opinion change. Strongly biased pro-European Union coverage in most Danish media led to corresponding opinion change, while more balanced coverage in the Netherlands and one Danish newspaper left readers unaffected. ${ }^{26}$ However, since both studies miss the critical data linking respondents with actual media consumed, media-persuasion cannot be unequivocally assessed in their designs.

The study we present here combines repeated measures of voters' opinions with information about the content of their preferred newspaper over the course of the campaign. We are, therefore, able to assess the influence British newspapers have on their readers - an influence that indeed proves to be substantial.

${ }^{22}$ Benjamin I. Page, Robert Y. Shapiro and Glenn R. Dempsey, 'What Moves Public Opinion?' American Political Science Review, 81 (1987), 23-43; David P. Fan and Albert R. Tims, 'The Impact of the News Media on Public Opinion: American Presidential Election 1987-1988', International Journal of Public Opinion Research, 1 (1989), 151-63; Dalton et al., 'Partisan Cues and the Media'; Neil T. Gavin and David Sanders, 'The Press and Its Influence on British Political Attitudes under New Labour', Political Studies, 51 (2003), 573-91; Agnieszka Dobrzynska, André Blais and Richard Nadeau, 'Do the Media have a Direct Impact on the Vote? The Case of the 1997 Canadian Election', International Journal of Public Opinion Research, 15 (2003), 27-43; Peter, 'Our Long Return to the Concept of Powerful Mass Media'; Druckman and Parkin, 'The Impact of Media Bias'; De Vreese and Boomgarden, 'Media Message Flow'.

${ }^{23}$ Druckman and Parkin, 'The Impact of Media Bias', p. 1031.

${ }^{24}$ Fan and Tims, 'The Impact of the News Media on Public Opinion'; Jan Kleinnijenhuis and David P. Fan, 'Media Coverage and the Flow of Voters in Multiparty Systems: The 1994 National Elections in Holland and Germany', International Journal of Public Opinion Research, 11 (1999), 233-56; Dobrzynska et al., 'Do the Media have a Direct Impact on the Vote?'

${ }^{25}$ Jan Kleinnijenhuis, Marcus Maurer, Hans Mathias Kepplinger and Dirk Oegema, 'Issues and Personalities in German and Dutch Television News: Patterns and Effects', European Journal of Communication, 16 (2001), 337-59.

${ }^{26}$ De Vreese and Boomgarden, 'Media Message Flow'. 
Before presenting our data and model, we need to address our dependent variable. The ultimate test of media persuasion in any given election is the extent that it can be shown to impact on actual vote choice, ${ }^{27}$ since 'the notion of success is embedded in the concept of persuasion'. ${ }^{28}$ But in doing so we risk searching only for the tip of the iceberg, ignoring substantial effects hidden under the surface. Over the course of the campaign, the media may affect people's attitudes towards parties, although not always to the point where voters will actually change their party preference. Nevertheless, readers may go from 'definitely not voting for that party' to 'might consider it' - a shift in party appreciation, although not yet consequential at the polling booth. At the next election, however, such a voter might be swayed from 'might consider' to 'will likely vote for this party'. An emphasis on vote choice may mean these more gradual effects of media influence remain undetected. To avoid this, we make use of party thermometer scores, a measure that allows for much finer distinctions in party support than the ipsative party choice measure. The precision of this measure is well suited to the precision of our research design. A refined measure of partisan sympathies allows us to trace the impact of the often subtle shifts in campaign coverage recorded in our content analysis.

The theoretical literature about the concept of persuasion supports this choice of dependent variable. Burnell and Reeve state that 'the strengthening or weakening of ... attachment to an existing position' is included in the definition of persuasion. ${ }^{29}$ In similar vein, O'Keefe states that 'even when a persuader's eventual aim is to influence what people $d o$..., at least in paradigm cases of persuasion that aim is ordinarily seen to be accomplished by changing what people think' ${ }^{30}$ Persuasion is a process of 'influencing others by influencing their mental states'. ${ }^{31}$

But, as will become clear from our research design and findings, a focus on how media influences mental states, through the strengthening or weakening of attitudes, does not mean that media effects are restricted to mere reinforcement or 'preservation of prior attitudes', as concluded in the Columbia studies. Gradual media-induced attitude change can be shown to contribute substantially to the making of electoral choices during a campaign.

\section{RESEARCH DESIGN AND DATA}

In this section, we will first discuss our main independent and dependent variables of interest: newspaper tone and party evaluation. We will then discuss additional variables included in our model, and the analytical structure.

We quantified the newspaper reporting of the 2005 campaign by means of a content analysis. We coded any mentioning of parties and party leaders, and also the tone (positive or negative) of these articles. The data describe the tone of reporting on party and party leaders in editorials and articles on the opinion pages ('op-ed') of seven national

27 Dobrzynska et al., 'Do the Media have a Direct Impact on the Vote?', p. 31; see also Lazarsfeld et al., The People's Choice; Kleinnijenhuis et al., 'Issues and Personalities in German and Dutch Television News'.

28 Daniel J. O'Keefe, Persuasion: Theory and Research, 2nd edn (Newbury Park, Calif.: Sage, 2002), p. 3. See also Douglas Walton, 'What is Propaganda, and What Exactly Is Wrong with It?' Public Affairs Quarterly, 11(1997), 383-413, p. 394; and Bryan Garsten, Saving Persuasion: A Defense of Rhetoric and Judgment (Cambridge, Mass.: Harvard University Press, 2006), pp. $2 \mathrm{ff}$.

${ }_{29}$ Peter Burnell and Andrew Reeve, 'Persuasion as a Political Concept', British Journal of Political Science, 14 (1984), 393-410, pp. 394-6.

${ }^{30}$ O'Keefe, 'Persuasion', p. 4.

31 O'Keefe, 'Persuasion', p. 5. 
daily newspapers (Daily Mail, Daily Mirror, Daily Telegraph, Guardian, Independent, Sun and The Times). ${ }^{32}$ All weekday (Monday-Saturday) issues published after the dissolution of parliament on 5 April up until election day on 5 May were included, and all articles on op-ed pages were coded for party and party leader references as well as the tone of any such reference. ${ }^{33}$ A deliberately conservative approach was taken when coding tone, with statements only coded as positive or negative if they contained a clear value judgement by the author(s) of the article. Hence, a statement to the effect that 'the polls and focus groups showed ... that Blair was unpopular and untrusted' would not be coded as a negative remark since it merely reports opinions that others have expressed. ${ }^{34}$ Only if an author openly criticized the behaviour or actions of a politician or party was this coded as negative; only if a politician or party was openly praised by the paper was the statement coded as positive. While we acknowledge that reporting of negative news or negative public opinion may hurt a party, in a media persuasion study we are explicitly interested in the power of newspapers to influence their readers directly through their political judgements. Hence, we restrict our coding to incidents of open and intentional bias. In the original content analysis, only op-ed pieces were coded for tone, to avoid more interpretive evaluations of content or frames that help or hurt one party. ${ }^{35}$ But, since prior research suggests a strong correlation between editorial tone and tendencies in news reporting, our selection of op-ed coding can be treated as sampling and the material used as a meaningful proxy for the overall partisan tendencies in newspapers. ${ }^{36}$ Assuming that actual bias will be weaker in news reporting than on opinion pages, a study exclusively focusing on op-ed pages is unproblematic, because it is rather prone to underestimating the true scale of effects.

For every article, single standardized lines of text formed the basic unit of measurement. ${ }^{37}$ Positive statements were given a score of +1 , neutral statements a zero and negative statements a -1 . Thus, we are able to calculate the average tone of any single article, and from that the average tone of a paper for any given day or week of the campaign. This is particularly relevant because it means we can go beyond campaign averages and match our respondents' attitudes during the campaign with the specific input they received up to that day. ${ }^{38}$ Our newspaper averages range between -1 and +1 and are comparable between newspapers and over time.

${ }^{32}$ We selected seven of the largest and most prominent newspapers to provide a sample of the British media landscape that accounts for variation in newspaper type (broadsheets, red-tops and black-tops) and partisan tendencies (Labour and Tory papers as well as newspapers with more ambiguous endorsements like the Independent).

${ }^{33}$ For an extensive description of the data, see Heinz Brandenburg, 'Party Strategy and Media Bias: A Quantitative Analysis of the 2005 UK Election Campaign', Journal of Elections, Public Opinion \& Parties, 16 (2006), 157-78.

${ }^{34}$ Larry Elliott, 'Why Alastair Campbell made Blair eat humble pie: Polls proved that only Gordon Brown could deliver a third Labour term', Guardian, 21 April 2005, p. 26.

${ }^{35}$ Brandenburg, 'Party Strategy and Media Bias'.

36 See Kahn and Kenney, 'The Slant of the News'.

37 We standardized text lines because columns width tends to vary within and between newspapers. Our standardization procedure consisted of multiplying the number of text lines of any data entry with its observed column width and then dividing by the average column width across the entire dataset.

${ }^{38}$ This design also allows us to assess the impact of the sheer volume of positive or negative evaluations, or the trade off between positive and negative reporting (in other words, whether, e.g., 20 positive versus 20 negative statements have a comparable effect to that of two or three positive and negative points). These measures were included in initial analysis but require further exploration and are not included in the analyses presented here. 
To measure the effect of this input, we make use of survey data collected before, during and after the 2005 general elections through the 2005 British Election Study (BES) campaign panel, an internet panel carried out by Yougov. The BES campaign panel consisted of three waves with respondents interviewed online, once before the official campaign started, then again at some stage during the campaign, and finally shortly after election day. ${ }^{39}$ Retention throughout the three stages was 76 per cent, resulting in a total of 4,894 respondents who completed all three interviews. We only include data from respondents who completed all three interviews and read one of our coded newspapers. Almost 75 per cent of our panel sample read a newspaper regularly. Of these, almost 80 per cent were readers of the seven coded newspapers.

The BES campaign data include information on a large number of personal characteristics including newspaper readership, and party evaluation via thermometer scores. For, each of the three main parties (Labour, Conservatives, Liberal Democrats), these thermometer questions ask respondents to give a score ranging from 0 (strongly dislike) to 10 (strongly like) to each party in all three waves of the panel. ${ }^{40}$

\section{What the Papers Say}

Table 1 gives an overview of the collected content data that we use for analysis here. ${ }^{41}$ Overall, a total of nearly 1,000 opinion pieces containing over 155,000 individual lines of text were coded. Around two-thirds of the text in these opinion pieces had references to political parties. As we can see, very little of the newspaper opinions about parties turned out to be positive.

As would be expected given the British media and political landscape at the time, the incumbent Labour government featured heavily in newspaper commentary and opinion pieces, with up to 60 per cent of all commentary directed at Labour. The Conservatives featured in 26 per cent of all text, the Liberal Democrats in 10 per cent, while other parties

${ }^{39}$ The use of internet panels remains subject to criticism because of limitations in the sampling and selection procedures of some of these panels, which it is said might result in violations of analytical assumptions or possible bias in the findings. However, in an extensive survey comparison, the team of researchers that conducted the 2001 and 2005 British Election Study addressed most of the contentious issues. They argued that, while on the one hand sampling problems remain with internet surveys because internet access is not randomly distributed, internet surveys on the other hand address some core problems with face-to-face surveys, for example by eliminating interviewer effects. They also found that while marginal distributions of key variables differ across both types of survey, when estimating parameters in vote choice and turnout models, face-to-face and internet surveys yield remarkably similar results. Also, issues of over- or under-representation of social groups appear to be dealt with effectively through weighting procedures in internet surveys carried out by Yougov. See David Sanders, Harold D. Clarke, Marianne C. Stewart and Paul Whiteley, 'Does Mode Matter for Modeling Political Choice? Evidence from the 2005 British Election Study', Political Analysis, 15 (2007), 257-85. Most importantly, however, our aim is to assess possible attitude change through media effects, which does not require our sample of newspaper readers to be nationally representative. For this reason, the graphs presented below, as well as subsequent regression models, are based on data that are not weighted to reflect nationally representative readership figures.

${ }^{40}$ Because of an error in the programming of the questionnaire for Wave 1, respondents were not actually able to give parties a score of 10 , but instead could only give a maximum score of 9 . In our analysis, this is addressed by applying a scale factor to the Wave 1 scores.

${ }^{41}$ Data included in our analysis comprise content analysis of op-ed pages only, since only these articles were coded for slant. The entire 2005 newspaper dataset is much larger and also contains content analysis of all news stories about the campaign (see Brandenburg, 'Party Strategy and Media Bias' for a description of the entire dataset). 
TA B LE 1 Overall Tone of Comments on Parties in the Seven Daily Newspapers Coded during the 2005 General Election Campaign

\begin{tabular}{lcccc}
\hline \hline Party & $\begin{array}{c}\text { No. of standardized } \\
\text { text lines }\end{array}$ & $\begin{array}{c}\text { Per cent } \\
\text { positive }\end{array}$ & $\begin{array}{c}\text { Per cent } \\
\text { neutral }\end{array}$ & $\begin{array}{c}\text { Per cent } \\
\text { negative }\end{array}$ \\
\hline Labour & 59,005 & 6 & 52 & 42 \\
Conservatives & 25,725 & 6 & 59 & 36 \\
Liberal Democrats & 10,954 & 4 & 56 & 40 \\
Other parties & 2,720 & 8 & 77 & 15 \\
Total & 98,404 & 6 & 55 & 39 \\
\hline
\end{tabular}

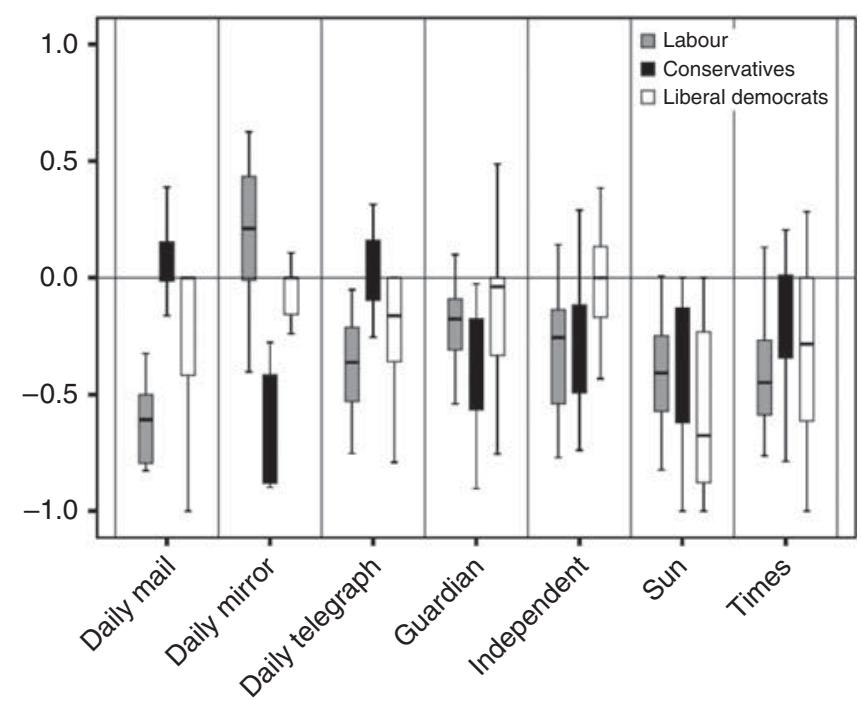

Fig. 1. Newspaper tone (partisan slant) during the 2005 campaign - mean scores and variation over the course of the campaign

were largely ignored. With regard to the tone of reporting in the newspapers, the amount of positive and negative judgements is roughly similar for all three major parties. The majority of comments about them are neutral, with around 40 per cent negative and only 4-6 per cent positive. References to other (minor) parties are overwhelmingly neutral.

Party treatment did vary markedly between newspapers. Figure 1, presenting average tone for the twenty-six days of the 2005 campaign, offers us various insights. ${ }^{42}$ The predominantly negative treatment of parties is a feature characteristic of most papers. But press partisanship lives on in Britain, underlined by the variation in support for parties between newspapers. Figure 1 also demonstrates that reliance on party endorsements as proxy for media content oversimplifies matters, as the intensity of this support, represented by the mean scores, varies substantially between newspapers.

42 Daily average tone scores were calculated from the coded text for each party in each newspaper $(n=26)$. Accordingly, the boxplots indicate the mean and quartile range calculated from twenty-six individual scores per party. 
Also of relevance is the substantial spread around the mean, indicating variation in a paper's party approval over the course of the campaign. Newspapers vary the intensity of their praise and criticism, and hence readers are subjected to differences in party treatment over the course of the election campaign.

Because newspaper tone varies over the campaign, we are able to circumvent an issue that might otherwise be encountered, namely the question of whether readers are influenced by their paper's partisan tendencies or choose their paper because of its known partisan stance. Readers can select a newspaper on the basis of what we will refer to as the 'house effect' of a newspaper: its average tone of reporting on a party. But readers cannot control the variation in this tone over the campaign period, which Figure 1 shows to be substantial. Thus, even if readers have selected a paper whose tone matches their own views, they are still exposed to various levels of intensity of a newspaper's tone of reporting on a party. Any effect of such variation in tone on partisan attitudes provides unambiguous evidence of media impact, because of its independence from overall partisan slant.

\section{What the Papers Say and What the Readers Think}

In the following analyses we assess whether and how much the media influence voters: to what degree did the tone of newspaper editorials and opinion articles affect how a respondent rated the three main parties over the course of the 2005 election campaign? Our main independent variable of interest is the tone of newspaper reporting. Our dependent variable is party evaluation. Feeling thermometer scores not only offer a more refined measure of partisan attitudes compared with vote choice, but they also suffer less from missing data since, especially in the early stages of the campaign, many respondents have not (yet) made a choice for one party. We analyse thermometer scores for each of the three main parties in three separate models, including only respondents who answered that party's feeling thermometer question in all three waves. Before explaining the operationalization of our newspaper variable and discussing the analytical model and findings, we will briefly introduce the control variables that we include in our models.

\section{Control Variables}

One of our main concerns is to avoid an endogeneity problem often inherent in the study of directional, persuasive media effects, namely to make sure that we do not ascribe an ambiguous causal impact to newspapers when a respondent may actually have chosen that paper specifically because of the opinions it voices. There are two ways to address this issue, via a fixed effects regression model, or, more traditionally, via inclusion of control variables. We will employ both methods and show that they lead to similar results.

We control for a number of key predictors of prior attitudes towards political parties. We include gender, age, income, education, class and party identification. Together, these constitute a well-specified model of party evaluations. For each respondent, the socioeconomic and demographic characteristics will not vary over the course of the campaign and are therefore held constant at the level established in the first wave. Individual party identification may in principle vary over the course of the campaign, as indeed it does, with levels of party identification increasing slightly between Waves 1 and 2 . However, here the panel data pose a problem because of a split-sample design in which a different question wording is used to assess party identification in Wave 1 and 2 for part of the sample, thus introducing a substantial design effect. Although we acknowledge that party 
identification may vary over the course of the campaign, we are therefore forced to classify our respondents on the basis of their party identification as measured in Wave 2 only, removing possible variation at the individual level for this control variable.

As further controls we include indicator variables for interviews held in Wave 2 and Wave 3. Initial analyses showed a substantial change in party evaluation especially from Wave 1 to Wave 2. In part this could be an artefact of the coding error mentioned earlier. However, a higher appraisal of political parties is not uncommon during the "feast of democracy' - in other words, during elections. ${ }^{43}$

While the focus of this article is the impact of newspaper slant on party evaluations, respondents are of course exposed to a more varied media landscape, as well as to campaign events and interpersonal conversations. With regard to the media, the most obvious additional source is television, while the internet continues to gain importance. We have no means of assessing the impact of the internet. We do have some means to assess the effect of television news coverage, albeit not in the way we would have liked, i.e., comparable to newspaper impact. The reason for this is that, although we have content-coded both ITV and BBC news broadcasts, the BES does not include an indicator on television viewing in the way it does for newspaper readership. As a result of this, we are only able to include television news as a control variable to assess the impact of newspaper tone accurately. Inclusion of both ITV and BBC news indicators leads to multicollinearity issues. Since the latter drew a larger audience, we include seven-day moving average scores of the BBC news tone on each party. ${ }^{44}$ The BES data do not allow us to control for campaign events or interpersonal conversations and we acknowledge that such other influences may well have a persuasive impact. Importantly, however, it is unlikely that these unobserved influences are confounding our media effects. While it would be crucial to control for external factors in, for example, an agenda-setting study in order to establish that media agendas are truly independent variables rather than responses to party agendas or reflections of campaign dynamics, this is less important with regard to media tone. Newspaper opinions and judgements are not simple reflections but biased interpretations of campaign events and dynamics, and as such they are highly unlikely to correlate fully with opinions expressed within a reader's personal network or conveyed through other channels. Thus, we are confident that the lack of detailed information on personal networks or additional news channels does not lead us to overestimate the effects of media tone.

\section{Newspaper Tone}

Different newspapers will vary in their tone towards parties. But newspapers will also vary in their tone towards a party over the course of a campaign. To acknowledge this, we

\footnotetext{
${ }^{43}$ Wouter van der Brug and Cees van der Eijk, 'De campagne deed er toe, mediagebruik niet', in Philip van Praag Jr and Kees Brants, eds, Tussen Beeld en Inhoud. Politiek en media in de verkiezingen van 1998 (Amsterdam: Het Spinhuis, 2000), pp. 214-42; Wouter van der Brug and Cees van der Eijk, 'Welke effecten hadden de campagnes nu eigenlijk?' in Kees Brants and Philip van Praag, eds, Politiek en Media in Verwarring. De verkiezingscampagnes in het lange jaar 2002 (Amsterdam: Spinhuis, 2005), pp. 244-67.

${ }^{44}$ In our content analysis of media channels, we also included evening news broadcasts on ITV and BBC. Since news broadcasts prove inherently more neutral than newspaper op-ed articles, the coding of television news differs from newspaper coding. In newspaper coding, any opinion voiced by anyone other than the author was not coded. However, television newscasts largely broadcast only such statements from party officials, experts or interviewed citizens, and therefore these statements were coded for partisan bias.
} 
include our media variables in pairs of two indicators. The first indicates the average tone of the newspaper at the start of the campaign. We may think of this as the 'house effect' of the paper: its general stance towards a party. This media indicator will explain party evaluation between readers of different papers.

The second media indicator is centred on the average newspaper tone. Hence, it indicates whether that paper was, before the timing of a respondent's interview, writing more positively or negatively about a party than it usually does. This second media indicator will explain variation within readers over the course of the campaign.

The benefit of this approach is that we are not only able to differentiate between readers of the different papers, on the basis of the 'house effects' (the first media indicator), but also able to establish the effect of variation in tone over the course of the campaign, within each newspaper. While the former is susceptible to endogeneity bias (which is why we include party identification as a control variable), the second variable is not affected by this because it controls for average tone (i.e., differences between newspapers). Thus, this second media variable is our most rigid test of possible media effects. ${ }^{45}$

The average tone of a newspaper can be calculated on a day to day basis. Since we know when each respondent was interviewed, we could calculate the average tone for that particular day and use this as media indicator for that respondent. However, that would suggest that respondents are only affected by what their paper writes on that particular day, ignoring all that went before, which seems unlikely. Hence, we base our media tone indicators on the average of the newspaper tone for the preceding seven days of the campaign. ${ }^{46}$ For the post-election interview, we use the average of the last seven days of the campaign. For the pre-campaign period, we face a slight problem as we do not have content analysis data for the pre-campaign period. Therefore, we use the average of the first three days of the campaign as proxy-indicator for the pre-campaign interview.

While we expect a respondent's opinion of a party to be affected by a paper's tone on that party, parties are in competition with each other, and hence voter's opinions may be affected by the media's tone on other parties as well. Ideally, we would therefore include information on all three major parties. While we have coded information on the paper's tone for the three major parties, a model including information on all three parties proves problematic, because of multicollinearity issues. ${ }^{47}$ Therefore, we include indicators for the paper's tone on the party and its main contender. ${ }^{48}$ Each model therefore includes two pairs of newspaper tone indicators: average newspaper tone, and variation around that average, for both parties.

\section{Who Is the Most Affected?}

There are two groups of readers who are of special interest to us: those who read their newspaper on a daily basis, and the undecided voters.

\footnotetext{
45 Note that in a fixed effects model the first media indicator is automatically created, and is redundant. The second media indicator is hence most reflective of the media indicator variable in a fixed effects model. In multilevel literature, the procedure is often referred to as group-mean centering. Cf. Paul D. Allison, Effects Regression Methods for Longitudinal Data Using SAS (Cary, N.C.: SAS Institute, 2005).

${ }^{46}$ For respondents interviewed during the first six days of the campaign, the average was based on the number of days in the campaign so far.

47 These multicollinearity issues stem largely from the fact that a newspaper treatment of a party over the course of the campaign tends to be related to its treatment of the other parties.

${ }^{48}$ For Labour and the Conservatives, tone on these two parties has been included. For the Liberal Democrats, separate models including tone on Labour or the Conservatives were run. Note that exclusion of tone on a third party does not reduce the explanatory power of the model.
} 
Potentially, daily readers may be most affected by a newspaper's tone, since 'getting the news is a prerequisite to being affected by the news', and they are exposed to it every day. ${ }^{49}$ Alternatively, though, they may be less affected, having grown familiar with and perhaps desensitized to the newspaper's tone over a longer period. They also tend to be more politically sophisticated, more partisan and hence more convinced of their views and not easily persuaded. ${ }^{50}$ Therefore, we treat this as an empirical question and test for the effect of reading the paper daily by including a dummy indicator, and interact it with newspaper tone. ${ }^{51}$

The second group of readers in whom we are particularly interested comprised the undecided voters. These are respondents who did not have an expressed party choice at the start of the campaign or who changed their preference over the course of it. We include in this group everyone who was undecided in Waves 1 and 2, who ultimately did not vote, or changed their vote choice between waves. About half of our respondents fit this category. Previous research leads us to expect the media to influence those involved in an active decision-making process more strongly than those who had already expressed a choice in Wave 1 and stuck with that choice through to polling day. ${ }^{52}$ Just as for daily readers, we include a dummy variable for undecided voters, and interact this with our newspaper tone variables. We expect the variation in tone over the course of the campaign to affect undecided voters more strongly. We do not necessarily expect a greater influence of 'house effects' (the average tone of a newspaper towards a party) for undecided voters, but it is worth testing for this nevertheless.

\section{Analytical Model}

Our analytical model is a multilevel regression model, taking into account the nested structure of the data. It models the repeated measurements - before, during and after the campaign - as nested within respondents to correct for the dependence of observations within respondents (intra-class correlations). We present findings from two types of multilevel models: first, a random effects multilevel regression including control variables; second, a fixed effects regression, where the model controls for variation between and respondents using instrumental dummy variables.

In the random effects multilevel regression we include a number of characteristics as control variables at the individual level (described above). Over the three waves of our panel, these characteristics do not vary within respondents, and they serve, therefore, to explain initial differences in feeling thermometer scores between respondents. In addition to these time-invariant characteristics, we also include characteristics that do vary over time: our media content indicators. These characteristics at the second level do vary over

49 Vincent Price and John Zaller 'Who Gets the News? Alternative Measures of News Reception and Their Implications for Research', Public Opinion Quarterly, 57(1993), 133-63, p. 158.

50 Zaller, 'Origins and Nature of Mass Opinion'.

51 At face value, it might seem desirable also to include non-readers as a control group whose opinion change over the campaign could serve as a baseline against which to assess media effects. Not only would this complicate the model specification but also, and more fundamentally, we are not proposing that readers as a whole are pushed in a direction different from that of non-readers. Rather, our models explain patterns of opinion change that result from specific media inputs - whether readers are actually persuaded by what their papers say. For that purpose, what matters are the differences in the messages readers are exposed to, and not any differences between the exposed and the unexposed.

52 Patrick Fournier, Richard Nadeau, André Blais, Elisabeth Gidengil and Neil Nevitte, 'Time-ofVoting Decision and Susceptibility to Campaign Effects', Electoral Studies, 23 (2004), 661-81. 
time, and hence they may explain variation in party thermometer scores over the course of the campaign. The model estimates a regression line for the whole of the sample while depending on the model specification - both the intercept and the slope may vary over individual respondents. The model will handle observations at different time points for different respondents, as is the case with our rolling panel.

While a random effects multilevel regression looks at variation both within and between respondents, in a fixed effects regression the emphasis is solely on variation within respondents over the course of the campaign. Fixed effects regression constitutes a more stringent test of media effects, since the impact of variables that do not vary over the course of the campaign is controlled for. Hence, we look at the impact of only those variables that vary within each respondent over the course of the campaign. ${ }^{53}$

\section{Findings}

Table 2 reports the findings from our analysis of party evaluation. The effects of media opinion on feelings towards parties are reported for each party in two separate models the first presenting controls and general media effects, the second including interactions between media effects and readership frequency as well as media effects and being an undecided voter. The table presents unstandardised parameter estimates and standard errors; statistically significant effects are flagged by asterisks. ${ }^{54}$

The parameter estimates for the constant in all three models show a distinct pattern: the Conservatives start from a very low average thermometer score, while the Liberal Democrats outperform Labour by a small margin. Although Labour almost catches up with the Liberal Democrats over the course of the campaign, there is no relief for the Tories, who fall further behind as the campaign proceeds, as the Wave 2 and 3 indicators make clear.

To summarize briefly the effect of our included control variables, we can, as expected, see how socio-economic and demographic factors affect thermometer scores differently for the three parties. Age matters for Labour, but not for the Tories or the Liberal Democrats. For Labour, the thermometer scores go down as respondents are older, indicating that Labour scored better among younger respondents. Gender has no significant effect on party evaluation for Labour and the Liberal Democrats, other factors held equal. Women hold a slightly more positive view of the Conservatives, but this effect is no longer significant if additional interactions are introduced to the model. Income does not significantly affect appreciation of the parties. ${ }^{55}$ For education, we see that having left school before the age of 16 is related to a higher appreciation of the Labour party and a lower appreciation of the Liberal Democrats, while a continued education after the age of 18 leads to significantly lower scores for the Conservatives. However, and in line with recent findings about the declining role of class in British politics, none of our class indicators prove significant. Party identification exerts a strong influence in the model for all three parties. There are no surprises here: party supporters - particularly those of the two main parties - evaluate their own party significantly more positively and other parties significantly more negatively; party identifiers do so to an even stronger degree than party 'leaners'. Of note is the Tories' predicament:

${ }_{53}$ Both the random and fixed effects estimates were obtained using STATA's xtreg.

${ }^{54}$ Table 2 presents the model for Liberal Democrats with media tone on Conservatives as the second party. The model with media tone on the Labour party is presented in the Appendix.

${ }_{55}$ We imputed the mean income for those respondents who failed to report their income. Since this estimate is not significant as well, these respondents show no significant difference in evaluation of the various parties. 
TA BLE 2 Newspaper Tone and Party Evaluations (Random Effects Models)

\begin{tabular}{|c|c|c|c|c|c|c|c|c|c|c|c|c|c|}
\hline & \multicolumn{4}{|c|}{ Labour } & \multicolumn{4}{|c|}{ Conservatives } & & \multicolumn{4}{|c|}{ Liberal Democrats } \\
\hline & \multicolumn{2}{|l|}{ I } & \multicolumn{2}{|l|}{ II } & \multicolumn{2}{|l|}{ I } & \multicolumn{2}{|l|}{ II } & & \multicolumn{2}{|l|}{ I } & \multicolumn{2}{|l|}{ II } \\
\hline & b & s.e. & b & s.e. & b & s.e. & b & s.e. & & b & s.e. & b & s.e. \\
\hline Constant & $3.34 * *$ & 0.20 & $3.40 * *$ & 0.22 & $2.20 * *$ & 0.02 & $2.17 * *$ & 0.22 & Constant & $3.87 * *$ & 0.21 & $3.77 * *$ & 0.21 \\
\hline Wave 2 indicator & $0.85 * *$ & 0.03 & $0.85 * *$ & 0.03 & $0.49 * *$ & 0.03 & $0.49 * *$ & 0.03 & Wave 2 indicator & $0.55 * *$ & 0.05 & $0.55 * *$ & 0.05 \\
\hline Wave 3 indicator & $0.90 * *$ & 0.05 & $0.90 * *$ & 0.05 & $0.48 * *$ & 0.04 & $0.48 * *$ & 0.04 & Wave 3 indicator & $0.55 * *$ & 0.08 & $0.55^{* * *}$ & 0.08 \\
\hline Undecided voters & $-0.38^{* *}$ & 0.08 & $-0.43 * *$ & 0.15 & 0.13 & 0.08 & 0.29 & 0.15 & Undecided voters & $0.38 * *$ & 0.08 & $0.58 * *$ & 0.11 \\
\hline Daily readers & $-0.23 * *$ & 0.08 & -0.25 & 0.15 & 0.19 * & 0.07 & 0.05 & 0.15 & Daily readers & $-0.39 * *$ & 0.08 & $-0.34^{* * *}$ & 0.11 \\
\hline Age (years since 18 ) & $-0.01 \% *$ & 0.00 & $-0.01 \% *$ & 0.00 & 0.00 & 0.00 & 0.00 & 0.00 & Age (years since 18 ) & -0.00 & 0.00 & -0.00 & 0.00 \\
\hline Female & -0.13 & 0.08 & -0.13 & 0.08 & 0.16 * & 0.08 & 0.15 & 0.08 & Female & 0.06 & 0.08 & 0.06 & 0.08 \\
\hline Income (centred around mean) & 0.00 & 0.00 & 0.00 & 0.00 & 0.00 & 0.00 & 0.00 & 0.00 & Income (centred around mean) & -0.00 & 0.00 & -0.00 & 0.00 \\
\hline Income-missing indicator & -0.17 & 0.12 & -0.15 & 0.12 & 0.09 & 0.12 & 0.08 & 0.12 & Income-missing indicator & -0.23 & 0.13 & -0.24 & 0.13 \\
\hline Education: left school before age 16 & $0.29 * *$ & 0.11 & $0.27 *$ & 0.11 & -0.10 & 0.11 & -0.09 & 0.11 & Education: left school before age 16 & $-0.31 * *$ & 0.11 & $-0.33^{* * *}$ & 0.11 \\
\hline Education: left school after age 18 & 0.12 & 0.09 & 0.11 & 0.09 & $-0.30 * *$ & 0.09 & $-0.29 * *$ & 0.09 & Education: left school after age 18 & 0.04 & 0.09 & -0.03 & 0.09 \\
\hline Class: professional $/$ managerial & -0.19 & 0.11 & -0.20 & 0.11 & -0.05 & 0.11 & -0.04 & 0.11 & Class: professional $/ \mathrm{managerial}$ & 0.02 & 0.11 & 0.03 & 0.11 \\
\hline Class: non-manual & -0.13 & 0.11 & -0.11 & 0.10 & 0.04 & 0.10 & 0.03 & 0.10 & Class: non-manual & 0.06 & 0.11 & 0.07 & 0.11 \\
\hline Class: petty bourgeoisie & -0.03 & 0.23 & -0.05 & 0.23 & -0.17 & 0.22 & -0.16 & 0.22 & Class: petty bourgeoisie & 0.20 & 0.23 & 0.19 & 0.23 \\
\hline Class: skilled manual & -0.19 & 0.14 & -0.23 & 0.14 & -0.06 & 0.14 & -0.03 & 0.14 & Class: skilled manual & 0.05 & 0.15 & 0.04 & 0.15 \\
\hline Party identifier: Labour & $3.82 * *$ & 0.11 & $3.76 * *$ & 0.11 & $-1.20 * *$ & 0.11 & $-1.16^{* *}$ & 0.11 & Party identifier: Labour & $0.99 * *$ & 0.12 & $0.95^{* * *}$ & 0.12 \\
\hline Party identifier: Conservatives & $-1.50 * *$ & 0.13 & $-1.43 * *$ & 0.13 & $4.32 * *$ & 0.12 & $4.29 * *$ & 0.12 & Party identifier: Conservatives & $-0.32 *$ & 0.13 & $-0.30 * *$ & 0.13 \\
\hline Party identifier: Liberal Democrats & $0.50 * *$ & 0.14 & $0.48 * *$ & 0.14 & $-0.47 * *$ & 0.14 & $-0.44 * *$ & 0.14 & Party identifier: Liberal Democrats & $3.45^{* *}$ & 0.14 & $3.41 * *$ & 0.14 \\
\hline Party leaner: Labour & $2.92 * *$ & 0.23 & $2.92 * *$ & 0.23 & 0.10 & 0.23 & 0.10 & 0.23 & Party leaner: Labour & $1.03 * *$ & 0.24 & $1.06 * *$ & 0.24 \\
\hline Party leaner: Conservatives & $-0.87 * *$ & 0.25 & $-0.86^{* * *}$ & 0.25 & $2.76 * *$ & 0.24 & $2.76 * *$ & 0.24 & Party leaner: Conservatives & -0.14 & 0.26 & -0.17 & 0.26 \\
\hline $\begin{array}{l}\text { Party leaner: Liberal Democrats } \\
\text { Newspaper tone }\end{array}$ & 0.28 & 0.23 & 0.27 & 0.23 & $-0.58 *$ & 0.23 & $-0.57 *$ & 0.23 & $\begin{array}{l}\text { Party leaner: Liberal Democrats } \\
\text { Newspaper tone }\end{array}$ & $2.25 * *$ & 0.24 & $2.24 * *$ & 0.23 \\
\hline Labour (paper average) & $0.77 * *$ & 0.17 & $0.98 * *$ & 0.31 & $-1.92 * *$ & 0.17 & $-2.09 * *$ & 0.31 & Lib Dem (paper average) & $3.38 * *$ & 0.38 & $1.76^{*}$ & 0.69 \\
\hline Labour (centred on average) & 0.30* & 0.15 & -0.22 & 0.28 & 0.05 & 0.13 & -0.03 & 0.25 & Lib Dem (centred on average) & -0.24 & 0.26 & -0.37 & 0.48 \\
\hline Conservatives (paper average) & $-1.21 * *$ & 0.28 & $-1.26 * *$ & 0.48 & $0.78^{* *}$ & 0.27 & $0.94 *$ & 0.47 & Conservatives (paper average) & $-1.01 * *$ & 0.32 & -0.95 & 0.56 \\
\hline Conservatives (centred on average) & -0.19 & 0.27 & -0.36 & 0.48 & -0.05 & 0.25 & 0.11 & 0.43 & Conservatives (centred on average) & 0.18 & 0.28 & -0.53 & 0.51 \\
\hline BBC Labour tone & 0.02 & 0.25 & 0.08 & 0.25 & 0.19 & 0.23 & 0.19 & 0.23 & BBC Lib Dem tone & -0.36 & 0.28 & -0.37 & 0.28 \\
\hline $\begin{array}{l}\text { BBC Conservative tone } \\
\text { Interactions }\end{array}$ & -0.03 & 0.23 & -0.04 & 0.23 & -0.17 & 0.21 & -0.17 & 0.21 & $\begin{array}{l}\text { BBC Conservative tone } \\
\text { Interactions }\end{array}$ & -0.08 & 0.26 & -0.09 & 0.26 \\
\hline Daily readers $\times$ Labour tone (avg) & & & $0.78 *$ & 0.33 & & & $-0.71 *$ & 0.33 & Daily readers $\times$ Lib tone & & & $3.14 * *$ & 0.73 \\
\hline Daily readers $\times$ variation Lab tone & & & 0.07 & 0.30 & & & -0.04 & 0.27 & Daily readers $\times$ variation Lib tone & & & -0.11 & 0.51 \\
\hline Daily readers $\times$ Con tone & & & $-1.37 * *$ & 0.50 & & & 0.24 & 0.49 & Daily readers $\times$ Con tone & & & $-1.35 *$ & 0.58 \\
\hline Daily readers $\times$ variation Con tone & & & 0.41 & 0.51 & & & -0.55 & 0.46 & Daily readers $\times$ variation Con tone & & & 1.09* & 0.54 \\
\hline Undecided $\times$ Lab tone & & & $-1.09 * *$ & 0.33 & & & $0.99 * *$ & 0.33 & Undecided $\times$ Lib tone & & & -0.11 & 0.73 \\
\hline Undecided $\times$ variation Lab tone & & & $0.95 * *$ & 0.30 & & & 0.18 & 0.27 & Undecided $\times$ variation Lib tone & & & 0.40 & 0.51 \\
\hline Undecided $\times$ Con tone & & & $1.58 * *$ & 0.49 & & & -0.60 & 0.49 & Undecided $\times$ Con tone & & & $1.32^{*}$ & 0.58 \\
\hline Undecided $\times$ variation Con tone & & & -0.13 & 0.51 & & & 0.30 & 0.46 & Undecided $\times$ variation Con tone & & & 0.23 & 0.54 \\
\hline$R^{2}$ overall & 0.56 & & 0.58 & & 0.61 & & 0.61 & & & 0.29 & & 0.30 & \\
\hline$R^{2}$ within & 0.16 & & 0.17 & & 0.07 & & 0.07 & & & 0.07 & & 0.08 & \\
\hline$R^{2}$ between & 0.62 & & 0.62 & & 0.65 & & 0.65 & & & 0.33 & & 0.34 & \\
\hline
\end{tabular}

Note: ${ }^{* *} p<0.01,{ }^{*} p<0.05$. 
Liberal Democrat supporters (both identifiers and 'leaners') evaluate the Tories negatively, while they merely rate Labour less highly as their preferred party.

We include dummy indicators for regular readers and for undecided voters. The findings vary substantially per party. For Labour, we find that daily readers are significantly less positive about the party, and undecided voters even more so, all other factors held equal. For the Conservatives, this pattern is exactly the reverse, although the effect is only significant for daily readers. Perhaps not surprisingly, the Liberal Democrats are more popular among undecided voters than among decided voters, although daily readers hold the Liberal Democrats in lower regard than those who do not read their paper every day. The estimates change as interactions are included in the model, as will be discussed below, although the direction remains the same in most cases.

As discussed already, these individual characteristics can explain differences in party evaluation between individual respondents. However, as these characteristics are stable over the course of the campaign, they cannot explain variation in thermometer scores within respondents during the campaign - something that the newspaper tone indicators can explain.

\section{Television and Newspaper Tone}

In none of our models does (BBC) television news tone exert a significant effect, but we retain the variable as a control nevertheless.

The newspaper tone indicator variables convey each paper's 'regular' tone on a party (the paper average indicator, based on tone in the first three days of the campaign), as well as the variation around that tone over the course of the campaign (the "centred on average' indicator). For each respondent, data from his or her particular newspaper is included, while per newspaper we include indicators on two of the three main parties to avoid multicollinearity issues (see debate in the previous section).

The estimates reveal strong media effects in line with expectations. Notably, we find that, for all parties, house effects (impact of a paper's average tone) are substantial and polarizing, particularly with regard to the two main parties. A positive tone on Labour has a positive effect on Labour thermometer scores but also a negative effect on Tory scores. The same holds for the Conservatives. This also implies that criticism of Labour increases the popularity of the Conservatives while criticism of the Tories improves ratings of Labour. In the model for the Liberal Democrats presented here, we see a similar polarized pattern, with a strong positive impact of treatment of the Liberal Democrats accompanied by a smaller but significant negative impact of treatment of the Conservatives. However, when Liberal Democrat evaluations are set off against the media tone towards Labour (see Appendix), no significant impact of cross-party treatment remains. In that model, only praise or criticism of the Liberal Democrats has the expected effect of increasing or depressing their thermometer scores. One might argue that, in the 2005 election, the British newspapers polarized their readers in line with a basic partisan cleavage that pitched the Conservatives against the other two parties.

It is also striking that, for the two main parties, negative house effects outweigh positive effects. Most notably, attitudes towards the Conservatives were influenced more by newspapers' treatment of Labour than by their treatment of the Conservative Party itself. Not only that, but the former effect was more than twice as large!

Next to the house effects, there are estimates for newspaper tone on each party as it varies over the course of the campaign. These are our direct tests for media persuasion. Here, we see that newspaper tone towards Labour positively and significantly affects 
attitudes towards the party. Regardless of how positively or negatively a newspaper tends to judge Labour on average, an even more positive or negative tone during the campaign significantly affects readers' evaluation of the party. The effect is substantially smaller than those of the house effects, and indeed for the other parties the estimates are not distinguishable from zero. With our current data, we are left to speculate that this may be caused by the dominance of the Labour party in this particular campaign.

\section{Regular and Undecided Readers}

We look at the impact of newspapers on regular readers and undecided voters in two types of models: an extension of the random effects models (also presented in Table 2) and through the use of fixed effects regression models, presented in Table 3 below. We test for additional media effects for these two groups by including interaction terms between the dummy indicators and the media variables.

For daily readers, the house effects are clearly more pronounced, as the interactions with the pre-campaign average show. The core readership is more in line with the newspaper's view on the respective parties, and for them in particular negative effects outweigh the positives. Indeed, their attitudes towards the Conservatives are only significantly and negatively influenced by the tone towards Labour. However, we do not find significant interactions for variation in the tone of newspapers over the course of the campaign, apart from a small positive effect of Conservative tone on Liberal Democrat appreciation among daily readers (which can, of course, also be read as a negative effect on occasional readers), where the overall impact of Conservative treatment is negative but insignificant.

For undecided voters, the story is reversed. Here, we see that the house effects are smaller: the significant interaction terms are in the opposite direction to the original parameters, indicating a diminished effect for undecided voters. However, this is not the case for the interaction with our second media indicator, assessing the variation of newspaper tone over the course of the campaign. Here, we see that the tone of newspaper reporting affects undecided voters more strongly than it affects voters who have already made up their mind. Again, what matters is newspaper tone on Labour, which significantly impacts on attitudes towards the party. Hence, a two-fold pattern of media influence emerges: regular readers, and those who have already made up their mind, are most affected by a newspaper's overall stance, while variation in tone over the course of the campaign actually affects those who are still in the process of finalizing their party choice.

Although the influence of variation in newspaper tone over the course of the campaign is the most convincing evidence of media persuasion, the house effects are of substantial importance as well. They can affect voters by reinforcing attitudes and potentially mobilizing supporters. In an increasingly fluid political landscape, this may actually be a media effect of increasing value to parties. As discussed above, although endogeneity cannot be excluded with certainty, we mitigate its effects through the inclusion of party identification and party preference indicators. In the fixed effects regression model, presented in Table 3, we take this control one step further.

\section{Robustness Test: Fixed Effects Model}

In fixed effects panel models the emphasis is on explaining variation within respondents, not between them. The model achieves this by including a dummy variable for each respondent (the estimates for which are not relevant and hence excluded from the table). The focus on variation within respondents implies that only those variables that vary over 
TAвLE 3 Fixed Effects Regression: Newspaper Tone and Party Evaluations

\begin{tabular}{|c|c|c|c|c|c|c|c|}
\hline & \multicolumn{2}{|c|}{ Labour } & \multicolumn{2}{|c|}{ Conservatives } & & \multicolumn{2}{|c|}{ Liberal Democrats } \\
\hline & $b$ & s.e. & $b$ & s.e. & & $b$ & s.e. \\
\hline Constant & $3.82 * *$ & 0.05 & $3.41 * *$ & 0.04 & Constant & $4.60 * *$ & 0.10 \\
\hline Wave 2 indicator & $0.86 * *$ & 0.03 & $0.49 * *$ & 0.03 & Wave 2 indicator & $0.53 * *$ & 0.05 \\
\hline Wave 3 indicator & $0.90 \div *$ & 0.05 & $0.49 * *$ & 0.05 & Wave 3 indicator & $0.52 * *$ & 0.08 \\
\hline Newspaper tone & & & & & Newspaper tone & & \\
\hline Newspapers Labour tone & -0.37 & 0.35 & 0.01 & 0.31 & Newspapers Lib Dem tone & -0.84 & 0.59 \\
\hline Newspapers Conservative tone & -0.38 & 0.59 & -0.06 & 0.52 & Newspapers Conservative tone & -0.15 & 0.63 \\
\hline BBC Labour tone & -0.03 & 0.26 & 0.25 & 0.23 & BBC Lib Dem tone & -0.55 & 0.29 \\
\hline $\mathrm{BBC}$ Conservative tone & -0.09 & 0.24 & -0.20 & 0.21 & $\mathrm{BBC}$ Conservative tone & -0.08 & 0.27 \\
\hline Interactions & & & & & Interactions & & \\
\hline Daily readers $\times$ Labour tone & 0.30 & 0.45 & -0.16 & 0.40 & Daily readers $\times$ LibDem tone & 0.57 & 0.77 \\
\hline Daily readers $\times$ Conservatives tone & 0.60 & 0.76 & -0.24 & 0.68 & Daily readers $\times$ Conservatives tone & 0.42 & 0.81 \\
\hline Undecided voters $\times$ Labour tone & $1.44 * *$ & 0.46 & 0.19 & 0.41 & Undecided voters $\times$ Lib tone & 1.05 & 0.78 \\
\hline Undecided voters $\times$ Conservatives tone & -0.36 & 0.79 & 0.42 & 0.71 & Undecided voters $\times$ Conservatives tone & -0.19 & 0.82 \\
\hline Daily $\times$ Undecided $\times$ Labour tone & -0.60 & 0.62 & 0.19 & 0.55 & Daily $\times$ Undecided $\times$ LibDem tone & -1.00 & 1.05 \\
\hline Daily $\times$ Undecided $\times$ Conservatives tone & -0.19 & 1.07 & -0.50 & 0.96 & Daily $\times$ Undecided $\times$ Conservatives tone & 0.77 & 1.11 \\
\hline$R^{2}$ overall & 0.02 & & 0.00 & & & 0.01 & \\
\hline$R^{2}$ within & 0.17 & & 0.07 & & & 0.08 & \\
\hline$R^{2}$ between & 0.00 & & 0.00 & & & 0.00 & \\
\hline
\end{tabular}

Note: $* * p<0.01, * p<0.05$ 
the course of the campaign are used to estimate the effects of interest. Differences between respondents, including party identification, are accounted for by the model so that possible endogeneity is addressed by the model set up.

As most of our control variables are constant over the campaign (either by nature, or because of the limitations of the survey), Table 3 presents estimates only for the Wave 2 and Wave 3 dummy indicators, the media variables, and their interactions with daily reader and undecided voter dummy indicators. In a fixed effects model, we no longer include our media variables in two parts - it ignores the (constant) pre-campaign average.

To completely rule out any endogeneity effects, the newspaper tone indicator is centred around the pre-campaign average. In effect, we are setting all initial newspaper tones to zero - and look only at variation of tone over the course of the campaign. Combined with the fixed effects regression taking into account variance between respondents, we believe this is the sternest test for media effects that non-experimental research will allow us. We find significant results for Labour, and in line with expectations: undecided voters are positively affected by the tone of their newspaper on Labour, regardless of the signature of their newspaper. Note that this explains only variation within respondents, which means that especially those who are still in the process of making a vote decision are responding systematically to changing media stimuli during the campaign.

What we see here is that centring the media variables in the fixed effects model removes the house effects, which matter more for decided voters and regular readers. This generates a quasi-experimental setting, which estimates responses to media stimuli that are entirely independent of average partisan bias. And we find that undecided voters are systematically sensitive to those stimuli, but only where the main party, Labour, is concerned.

\section{Scale and Impact of House and Campaign Effects}

The findings from fixed effects models show that attitudes of undecided voters towards the Labour party are driven by trends in bias during the campaign. The latter short-term campaign effects are the most unambiguous incidents of media persuasion. But what difference does this make for our readers? We evaluate this in Figure 2, which shows the predicted thermometer score for Labour, for decided and undecided voters, set off against that reader's newspaper tone on Labour (centred, ranging from -1 to +1 ), based on the fixed effects model, which centres the newspaper tone and hence controls for the overall bias in any newspaper.

Since no further explanatory variables are included that can distinguish between voters, the spread around the slope is very small and the model underestimates the average thermometer score, but we are interested in the slope here. We see that decided voters are virtually unaffected by variation in newspaper tone over the course of the campaign (the slope is slightly negative, but not statistically significant). For undecided voters we see a clear upward trend: regardless of the initial tone of their newspaper, undecided voters are more positive about Labour if their newspaper writes more positively about the party, and more negative if it writes more negatively about the party over the course of the campaign. This is controlling for any prior party preferences. As Figure 2 illustrates, when newspaper tone changes from -0.2 to +0.4 , thermometer scores increase by half a point. That this is not a trivial increase becomes apparent when we look at Table 4.

Table 4 presents Labour's average thermometer score among decided and undecided voters who eventually chose Labour. Two features are striking. First, there is a substantial difference in thermometer scores between decided and undecided voters, which, although 

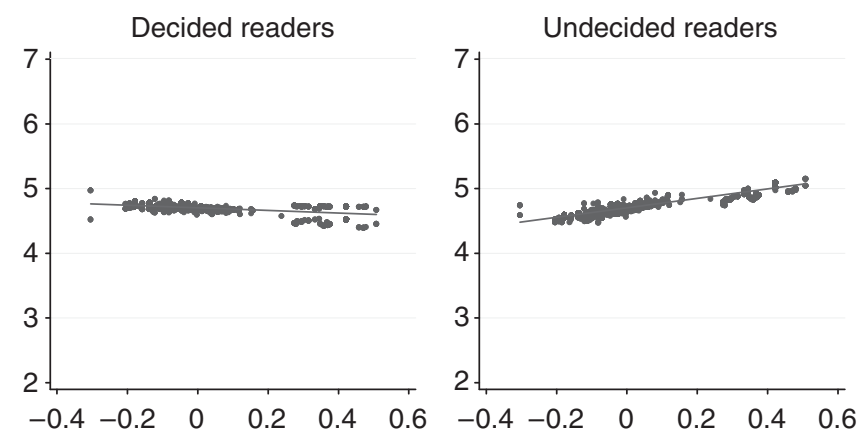

Fig. 2. Predicted Labour thermometer scores against centred newspaper tone

TA B LE 4 Average Thermometer Score for Labour per Wave, for Those Who Eventually Voted Labour, for Decided and Undecided Voters

\begin{tabular}{lccc}
\hline \hline & Wave 1 & Wave 2 & Wave 3 \\
\hline Decided voters & 7.8 & 8.3 & 8.3 \\
Undecided voters & 5.3 & 6.5 & 6.8 \\
\hline \hline
\end{tabular}

not necessarily surprising, emphasizes that there is a substantial difference in Labour's popularity between these groups of voters. But second, and more importantly, we see very different trends for both groups of voters. The Labour ratings from decided voters do improve, but only between Waves 1 and 2 and only to a small degree. This helps to explain why we find no media impact on decided voters in the fixed effects model (see Figure 2, left panel). The ratings of undecided voters increase more substantially but, in order eventually to choose Labour, still only an improvement of one and a half points is required. This puts the effect shown in Figure 2 in perspective: an improvement of tone by a quarter of the range (from -0.2 to +0.4 ) accounts for an increase in party evaluation of about a third of what is required to sway an undecided voter. In other words, while the absolute changes may appear small, their impact - net of other campaign efforts - can be substantial for the group of voters most susceptible to persuasion.

\section{CONCLUSIONS}

Our findings strengthen the argument that it matters politically which paper you read, and even more so what that paper writes. Clearly, newspapers attract a certain readership and may well aim to publish opinions that can be expected to resonate with that readership. Nevertheless, we find clear effects of the stances a paper takes towards each of the main parties, and indeed an effect of differences in such stances between newspapers, even between those that are generally understood to be on the same side in the political battle. Even more pertinently, it emerges that a newspaper's treatment of a party affects not only how readers evaluate that party but also how they rate its competitors. For the big parties, Labour and Conservatives, negative effects outweigh positive effects - in the sense that each party benefits more from criticism of its opponent than from direct support. 
From this one can deduce that relentless media criticism of a party during a campaign does not seriously undermine that party's popularity, but does more damage by improving the ratings of its rivals. Much of the polarized coverage in partisan papers may be dismissed as preaching to the converted, but our findings suggest that such divergent treatment of parties has a reinforcing and potentially mobilizing effect by strengthening pre-existing attitudes.

More importantly, however, our study shows quite conclusively that newspaper bias matters for opinion formation or change. Irrespective of the kind of newspaper that a respondent reads, the more positive the tone towards the incumbent party at the time of the interview, the higher is that respondent's like-dislike rating of Labour. Equally, the more negative the reporting at the time directly preceding the interview, the deeper the slump in the respondent's opinion of Labour. And most notably, this effect only remains for those still making up their minds during the campaign once we separate between decided and undecided voters. Reinforcing media effects explain differences between respondents and do so mostly for decided voters. But opinion formation is a matter of within-respondent variation and change, and media influence only explains such withinrespondent variation for those who are still in the process of forming an opinion. Recall that this is evidence for a direct link between party treatment in a newspaper and subsequent reader attitudes towards parties, a link that is completely independent of the overall political stance of that paper. Through centring newspaper tone around the stance of a paper at the very beginning of the campaign, we are effectively running a blind test of how sensitive readers are to variations in slant over the remainder of the campaign, irrespective of whom the readers are or which newspaper they read. We find undecided voters to be sensitive enough to such variation that it makes a substantial contribution to the kind of attitude change that could bring about their ultimate vote choice. This is clear evidence of media persuasion, not merely framing or agenda setting.

These findings are highly encouraging, but they provide only a starting point. While improving on studies that use proxies like media exposure or newspaper endorsements for actual content, we still have to contend with some limitations ourselves. For example, we needed to use a proxy for the missing content analysis data from the pre-campaign wave.

Also, the size of the panel study in 2005 does not allow us to model a newspaper's specific partisan stance or trajectory of endorsement over the course of the campaign separately, to determine the impact a particular paper may have had on its readers. Instead, we report findings that combine the effects of seven of the main national dailies. This may actually result in underestimating the true impact of individual newspapers on their readers. In the near future, we hope to be able to use input and output data that cover the entire period for which such a three-wave rolling campaign panel is carried out, also having access to a much larger panel study. This will increase the leverage of our model, enable the testing of impact over a longer time-frame, and allow still closer modelling of the dynamics of message and response mechanisms. 
APPENDIX

TABLE A $1 \quad$ Newspaper Tone and Party Evaluations, Liberal Democrats v. Labour (Random Effects Models)

\begin{tabular}{|c|c|c|c|c|}
\hline & \multicolumn{4}{|c|}{ Liberal Democrats } \\
\hline & \multicolumn{2}{|c|}{ Model I } & \multicolumn{2}{|c|}{ Model II } \\
\hline & $b$ & s.e. & $b$ & s.e. \\
\hline Constant & $4.12 \% *$ & 0.20 & $4.00 \div *$ & 0.21 \\
\hline Wave 2 indicator & $0.55 * *$ & 0.05 & $0.55 * *$ & 0.05 \\
\hline Wave 3 indicator & $0.53 * *$ & 0.06 & $0.53 * *$ & 0.06 \\
\hline Undecided voters & $0.38 * *$ & 0.08 & $0.36 * *$ & 0.12 \\
\hline Daily readers & $-0.39 * *$ & 0.08 & -0.09 & 0.12 \\
\hline Age (years since 18) & -0.00 & 0.00 & -0.00 & 0.00 \\
\hline Female & 0.07 & 0.08 & 0.07 & 0.08 \\
\hline Income (centred around mean) & -0.00 & 0.00 & -0.00 & 0.00 \\
\hline Income-missing indicator & -0.24 & 0.13 & -0.24 & 0.13 \\
\hline Education: left school before age 16 & $-0.29 * *$ & 0.11 & $-0.30 * *$ & 0.11 \\
\hline Education: left school after age 18 & 0.01 & 0.09 & -0.00 & 0.09 \\
\hline Class: professional/managerial & 0.00 & 0.11 & 0.01 & 0.11 \\
\hline Class: non-manual & 0.05 & 0.11 & 0.06 & 0.11 \\
\hline Class: petty bourgeoisie & 0.19 & 0.23 & 0.19 & 0.23 \\
\hline Class: skilled manual & 0.05 & 0.15 & 0.05 & 0.15 \\
\hline Party identifier: Labour & $1.01 * *$ & 0.12 & $0.99 * *$ & 0.12 \\
\hline Party identifier: Conservatives & $-0.34 * *$ & 0.13 & $-0.34 * *$ & 0.13 \\
\hline Party identifier: Liberal Democrats & $3.46^{* * *}$ & 0.14 & $3.42 * *$ & 0.14 \\
\hline Party leaner: Labour & $1.04 * *$ & 0.24 & $1.07 * *$ & 0.24 \\
\hline Party leaner: Conservatives & -0.17 & 0.26 & -0.18 & 0.26 \\
\hline Party leaner: Liberal Democrats & $2.26 * *$ & 0.24 & $2.25 * *$ & 0.24 \\
\hline \multicolumn{5}{|l|}{ Newspaper tone } \\
\hline Lib Dem (paper average) & $2.10 * *$ & 0.45 & 0.72 & 0.79 \\
\hline Lib Dem (centred on average) & -0.14 & 0.22 & -0.62 & 0.40 \\
\hline Labour (paper average) & 0.43 & 0.23 & 0.33 & 0.41 \\
\hline Labour (centred on average) & -0.09 & 0.13 & -0.22 & 0.24 \\
\hline BBC Lib Dem tone & -0.43 & 0.29 & -0.43 & 0.29 \\
\hline BBC Labour tone & -0.00 & 0.29 & -0.01 & 0.29 \\
\hline \multicolumn{5}{|l|}{ Interactions } \\
\hline Daily readers $\times$ Lib tone & & & 1.13 & 0.84 \\
\hline Daily readers $\times$ variation Lib tone & & & 0.45 & 0.43 \\
\hline Daily readers $\times$ Labour tone (avg) & & & 0.74 & 0.43 \\
\hline Daily readers $\times$ variation Lab tone & & & 0.16 & 0.26 \\
\hline Undecided $\times$ Lib tone & & & 1.53 & 0.83 \\
\hline Undecided $\times$ variation Lib tone & & & 0.50 & 0.43 \\
\hline Undecided $\times$ Lab tone & & & -0.57 & 0.43 \\
\hline Undecided $\times$ variation Lab tone & & & 0.11 & 0.26 \\
\hline$R^{2}$ overall & 0.29 & & 0.29 & \\
\hline$R^{2}$ within & 0.07 & & 0.07 & \\
\hline$R^{2}$ between & 0.33 & & 0.34 & \\
\hline
\end{tabular}

Note: $* * p<0.01, * p<0.05$. 
TABLE A $2 \quad$ Fixed Effects Regression: Newspaper Tone and Party Evaluations, Liberal Democrats v. Labour

\begin{tabular}{lcc}
\hline \hline & \multicolumn{2}{c}{ Liberal Democrats } \\
\cline { 2 - 3 } & $b$ & s.e. \\
\hline Constant & $\mathbf{4 . 6 1 * *}$ & $\mathbf{0 . 1 3}$ \\
Wave 2 indicator & $\mathbf{0 . 5 4 * *}$ & $\mathbf{0 . 0 5}$ \\
Wave 3 indicator & $\mathbf{0 . 5 0 * *}$ & $\mathbf{0 . 0 6}$ \\
Newspaper tone & & \\
Newspapers Lib Dem tone & -0.90 & 0.48 \\
Newspapers Labour tone & -0.08 & 0.30 \\
BBC Lib Dem tone & -0.57 & 0.30 \\
BBC Labour tone & -0.09 & 0.30 \\
Interactions & & \\
Daily readers $\times$ LibDem tone & 0.78 & 0.63 \\
Daily readers $\times$ Labour tone & 0.08 & 0.39 \\
Undecided voters $\times$ Lib tone & 0.95 & 0.64 \\
Undecided voters $\times$ Labour tone & -0.05 & 0.89 \\
Daily*Undecided $\times$ LibDem tone & -0.62 & 0.53 \\
Daily*Undecided $\times$ Labour tone & 0.11 & \\
$R^{2}$ overall & 0.01 & \\
$R^{2}$ within & 0.08 & \\
$R^{2}$ between & 0.00 & \\
\hline \hline
\end{tabular}

Note: ${ }^{* *} p<0.01,{ }^{*} p<0.05$. 